Research Article

\title{
Slope Stability from a Hydrological Perspective: Taking Typical Soil Slope as an Example
}

\author{
Yuelu Zhu ${ }^{1,2}$ and Yaoting Xiao $\mathbb{1}^{3}$ \\ ${ }^{1}$ China Institute of Water Resources and Hydropower Research, Beijing 110038, China \\ ${ }^{2}$ College of Water Conservancy and Ecological Engineering, Nanchang Institute of Technology, Nanchang 330099, China \\ ${ }^{3}$ College of Civil Engineering and Architecture, Hubei University of Arts and Science, Xiangyang 441053, China
}

Correspondence should be addressed to Yaoting Xiao; xiaoyaoting1983@163.com

Received 16 January 2020; Accepted 25 April 2020; Published 14 May 2020

Academic Editor: Castorina S. Vieira

Copyright (C) 2020 Yuelu Zhu and Yaoting Xiao. This is an open access article distributed under the Creative Commons Attribution License, which permits unrestricted use, distribution, and reproduction in any medium, provided the original work is properly cited.

In the traditional research of slope stability, it is difficult to continuously obtain the moisture content of soil in long time sequences. In combination with the precipitation, temperature, and vegetation cover data in the study area, the variable infiltration capacity hydrological model is used to estimate the daily variation of soil moisture content, which is used as a calculation condition for the analysis of slope stability. The results show that, from 1970 to 2010, the spatial-temporal distribution of soil moisture content in the Weihe River Basin showed an increasing trend. Moreover, the shear strength of soil decreased, but the range was stable at approximately $2 \%$. The strength reduction method based on the M-C inscribed circle criterion (DP3) shows that the slope stability factor $k$ had an increasing trend for over $40 \mathrm{y}$. The portion of the period with a $k$ value higher than 1.2 is more than $85 \%$ of the entire period, that with a $k$ value between 1 and 1.2 is approximately $9 \%$, and that with a $k$ value less than 1 is approximately $5.5 \%$. The R/S analysis results show that the Hurst coefficients of the $\tau$ - $t$ curve and the $k$ - $t$ curve are 0.5568 and 0.5888 , respectively, and that the slope is in a state of no variation. Based on these factors, the present and future of the slope is in a stable state. This scheme is a method of studying slope stability based on hydrology, and it provides a modern alternative for soil shear strength calculation and geological hazard assessment.

\section{Introduction}

Increasingly frequent human activities and the acceleration of industrialization process have significantly affected the natural environment. As a result, the damage caused by environmental changes has adversely affected the human society. Geological disasters are a form of drastic environmental change that often cause considerable losses to urban construction and engineering projects and affect the safety of people's lives and property. Besides earthquakes, landslides are the most harmful geological disasters. According to the incomplete statistics worldwide, tens of thousands of casualties and tens of billions of dollars as economic losses are caused by landslides every year, thereby greatly hindering the development of engineering construction and urbanization. According to the data released by the Chinese government covering the period from 2014 to 2017, the annual proportion of landslides in various geological disasters is $74.5 \%, 68.13 \%, 76.2 \%$, and $50.2 \%$, respectively. Notably, for China, where mountainous areas account for approximately two-thirds of the total land area, it is an urgent issue to study, manage, and predict the risks caused by various landslides. Similarly, timely prevention and mitigation of disasters is also important.

One of the important factors affecting slope stability is the soil moisture content. Consequently, engineering accidents caused by the decrease in soil shear strength due to the increase in moisture content are very common. In the Loess Plateau of Western China, rainfall is the most important and commonly inducing factor of landslide [1]. Therefore, research on the relationship between moisture content, shear strength, and slope stability has been an important topic in the engineering field [2-4].

Ali et al. [5] believed that simulating the distribution of moisture content and seepage field in landslides is a prerequisite for slope stability calculation. The Institute of 
Geotechnical Engineering of Hehai University [6] has designed a calculation method for the initial moisture content, which can accurately estimate the permeability strength. Liao et al. [7] analyzed the change in the slope seepage field caused by different rates of water level rise and obtained the change rule of the slope safety coefficient $k$ by using the principle of limit equilibrium. Rahimi and Faza [8] calculated the slope stability by using the moisture content of long-term small intensity rainfall on the simulation test site. However, Segoni et al. [9] considered that although the small-scale rainfall simulation test is easy to operate, the initial moisture content obtained by the test is quite different from the measured value and that the parameters assumed in the numerical calculation are too high, which is not in line with the actual situation. Therefore, Xian and Yang [10] established a fluid-solid coupling model of landslide mass by using moisture content measured on site and put forward suggestions for early warning of landslides.

Some scholars have defined the landslide induced by water as "rainfall landslide." Although this definition is still controversial, it shows that water is the main cause of landslides. Based on the preliminary hydrological data of the Three Gorges Reservoir Area, Tang [11] simulated the initial moisture content of the slope and analyzed the influence of different rainfall intensities on the slope stability by using the GeoStudio software. Zhang [12] continued this study one step further by performing a laboratory simulation test of rainfall infiltration and conducting a stability analysis under the coupling of runoff and seepage. This study involved the concept of "runoff" in the hydrological field. However, this study was unable to explain the relationship between the meteorological factors, underlying surface factors, and runoff. Sun [13] classified unsaturated soil landslides in Chongqing based on the geographic information system (GIS), in addition to the moisture content. Furthermore, Sun considered four indicators related to the hydrology, i.e., normalized difference vegetation index (NDVI), water system, land-use type, and multiyear average rainfall. In this study, geotechnical engineering and hydrology are combined to classify landslide mass and to predict its risk. However, this study only statistically analyzes the correlation between each index and 1520 landslide data in history, without further discussion on the mechanism.

Presently, in the study of slope stability, the shear strength of soil is mostly discussed based on mechanics. In contrast, it discusses the physical effect of water, which increases the bulk density of soil and leads to slope sliding. Moreover, it analyzes the softening effect of water flow, which reduces the shear strength of the soil.

The traditional research method is a powerful tool for evaluating the shear strength of soil and the slope stability, but it still has some limitations. First, the landslide body is extracted from the space as a separate body, thereby ignoring the relationship between the landslide and the surrounding environment. Moreover, the error has been formed when the model was established, and thus it cannot be reduced by calculation. Second, the research method of soil shear strength, which only considers soil type and moisture content, ignores the influence of atmospheric precipitation, land surface evaporation, vegetation cover, terrain change, and other factors on the stress history. Furthermore, the traditional finite element software is unable to consider these factors. Third, in the formation history of any soil mass, the soil moisture content is dynamic. Consequently, the shear strength of soil is also dynamic. However, due to the limitation of measurement methods or remote geographical location, it is difficult to conduct continuous monitoring, and hence the dynamic process can only be reduced to a static process. Hence, the results cannot truly reflect the temporal and spatial changes of soil shear strength. Fourth, a single geotechnical perspective will inevitably lead researchers to focus on the final result of slope calculation, i.e., "destruction or safety." Evidently, the binary conclusion of the "zero-sum game" is not the optimal solution for the evolution of the landslide body. Fifth, presently the slope stability research focuses on factor analysis, but where these factors (e.g., water in unsaturated soils) arise in a particular area and whether they appear are not considered enough and are often limited to qualitative discussions in terms of interdisciplinarity.

Based on the foregoing understanding, according to the hydrological theory and applying the data on meteorology, soil, and vegetation distribution in the study area, this study uses the large-scale semidistributed hydrological model variable infiltration capacity (VIC) to construct the spatialtemporal distribution model of soil moisture content for each layer of the study area. Based on the soil moisture database generated by the model, through the finite element simulation of the slope, the shear strength of the soil and the slope stability are finally evaluated.

There are three characteristics in this method: first, in the hydrological model, the soil moisture content of the grid in the study area is generated via the confluence of the surrounding grid, which is closely related to the surrounding environment and more in line with the actual conditions; second, the moisture content data of the spatial-temporal distribution model comes from the simulation results of the hydrological model, which is not limited by the measured data, with the generated soil moisture content being continuously distributed in the spatial-temporal sequence, thereby avoiding the shortcomings of the static moisture content experiment; and third, the hydrological model and the slope finite element model are combined to establish the relationship between the hydrological model data and the key parameters $c$ and $\varphi$ in the slope finite element model to build a closed calculation chain, in theory. The application of the hydrological model in the research field of slope stability provides a new method for the study of slope treatment.

\section{Study Area and Data}

2.1. Model, Basin, and Data. The VIC hydrological model [14-16] is a land surface hydrological model mutually developed by Washington University, UC Berkeley, and Princeton University. Large scale, distribution, and several influencing factors are the main characteristics of this model at this stage. Through the subgrid input of different climate data and underlying surface data, the model can simulate 
and generate the daily evaporation, moisture content, and other data of each grid, and finally generate the daily and monthly runoff data of the outlet section through the confluence program. The applicability of the model has been repeatedly verified in various basins around the world.

In this study, the Weihe River Basin was taken as the study area. Moreover, the rainfall, temperature, wind speed, and other data from 21 meteorological stations in the basin from 1960 to 2010 were used as the basic input data. Based on the semidistributed hydrological model, the basin is divided into 75 grids with a size of $0.5^{\circ} \times 0.5^{\circ}$, as shown in Figure 1. The 14 types of land cover with an accuracy of $1 \mathrm{~km}^{2}$ were used to construct the vegetation database, which contains various parameters of the corresponding vegetation. When there is a certain type of vegetation in the grid, the program assigns the value to be true. The soil layer in each grid is divided into three layers, where $d_{1}$ is 0.1 , whereas $d_{2}$ and $d_{3}$ need to be obtained through parameter calibration.

2.2. Location and Plan of Landslide Body. In this study, the landslide body is located in a grid composed of $34^{\circ} \mathrm{N}-34^{\circ} 30^{\prime} \mathrm{N}$ and $107^{\circ} \mathrm{E}-107^{\circ} 30^{\prime} \mathrm{E}$ in the VIC model. The region has complex topography and landform, with 68 landslides on both sides of the river. In some areas, hidden dangers are serious, and landslides are densely distributed. As a result of human activities and climate change, the soil moisture content of the landslide body changes constantly, aggravating the risk of landslides. The location and plan of the landslide body in the study area are shown in Figure 2.

2.3. Soil Monitoring Station Data in the Study Area. In order to ensure the accuracy of the VIC model output, the actual moisture content data of the Baoji monitoring station from 1981 to 1991 were compared with the average moisture content of the grid generated by simulation (the landslide body in this study is within the grid) [17]. The distribution of soil monitoring stations in China and the locations of selected stations in this study are shown in Figure 3.

\section{Methods}

3.1. Parameter Calibration of the VIC Model. The purpose of model parameter calibration is to test the rationality of the soil moisture content generated in the grid. Owing to the limitation of the model mechanism, the correctness of the calculation results of soil moisture content cannot be directly tested. Therefore, the rationality of the soil moisture content is verified by the confluence results. If the confluence results are verified, the results of soil moisture content are considered reasonable. In this study, the parameters of the VIC model are calibrated using the uniform design theory. Moreover, the traditional calibration interval is reorganized by the number theory to determine the optimal combination of basin parameters. The basic steps of the uniform design theory are (1) determine the calibration factors and the number of levels corresponding to each factor; (2) select the appropriate uniform design table according to the factors and levels; and (3) arrange the test according to the selected uniform design table and conduct the effect inspection. This study refers to the research results of Zhu and Chang [18] and uses the $U^{*}{ }_{10}(10)^{8}$ scheme to calibrate the parameters of the study area (see references $[19,20]$ for the uniform design table and its application table). After the initial determination of the parameters, to determine whether the calibration parameters are reasonable, the total accuracy error and the Nash efficiency coefficient widely used in the hydrological field are selected as the test functions.

(1) Total accuracy error $E_{\mathrm{r}}$ (\%) represents the fitting degree of the simulated and measured runoff, and it is expressed as follows:

$$
E_{\mathrm{r}}=\frac{\left(\overline{Q_{\mathrm{c}}}-\overline{Q_{0}}\right)}{\overline{Q_{0}}},
$$

where $\overline{Q_{0}}$ is the annual average value of the measured runoff $(\mathrm{mm})$ and $\overline{Q_{c}}$ is the annual average value of the simulated runoff $(\mathrm{mm})$.

(2) The Nash efficiency coefficient $C_{\mathrm{e}}$ represents the fitting degree of the simulated and measured runoff processes on the timeline, and it is expressed as follows:

$$
C_{\mathrm{e}}=\frac{\sum\left(\mathrm{Q}_{\mathrm{io}}-\overline{\mathrm{Q}_{0}}\right)^{2}-\sum\left(\mathrm{Q}_{\mathrm{ic}}-\mathrm{Q}_{\mathrm{io}}\right)^{2}}{\sum\left(\mathrm{Q}_{\mathrm{io}}-\overline{\mathrm{Q}_{0}}\right)^{2}},
$$

where $Q_{i o}$ is the measured runoff process, $\mathrm{m}^{3} / \mathrm{s}$, and $Q_{i c}$ is the simulated runoff process, $\mathrm{m}^{3} / \mathrm{s}$.

The closer the value of $E_{\mathrm{r}}$ is to 0 and the closer the value of $C_{\mathrm{e}}$ is to 1 , the closer the parameters are to the actual situation and the more accurate the model simulation is.

3.2. Fitting of Soil Shear Strength. In this study, the soil moisture content generated by the VIC model was substituted into the fitting formula in reference [21] to calculate and generate the set of dynamic model parameters, $c$ and $\varphi$. This group of dynamic parameters is an important basis for calculating the shear strength-time curve ( $\tau$ - $t$ curve) and the slope stability coefficient. The fitting formula is expressed as follows:

$$
\begin{aligned}
\tau & =c(w)+\sigma \tan \varphi(w), \\
c(w) & =a w^{2}+b w+c, \\
\varphi(w) & =\mathrm{d} w+e,
\end{aligned}
$$

where $w$ is the moisture content, $c$ is the cohesion, $\varphi$ is the internal friction angle, $\tau$ is the shear strength, and $a, b$, and $c$ are the coefficients.

The research results present the following inferences: (1) the relationship between shear strength and moisture content is negative overall, i.e., when the moisture content is high, the shear strength is low, which is very significant in some intervals; (2) within the specified 


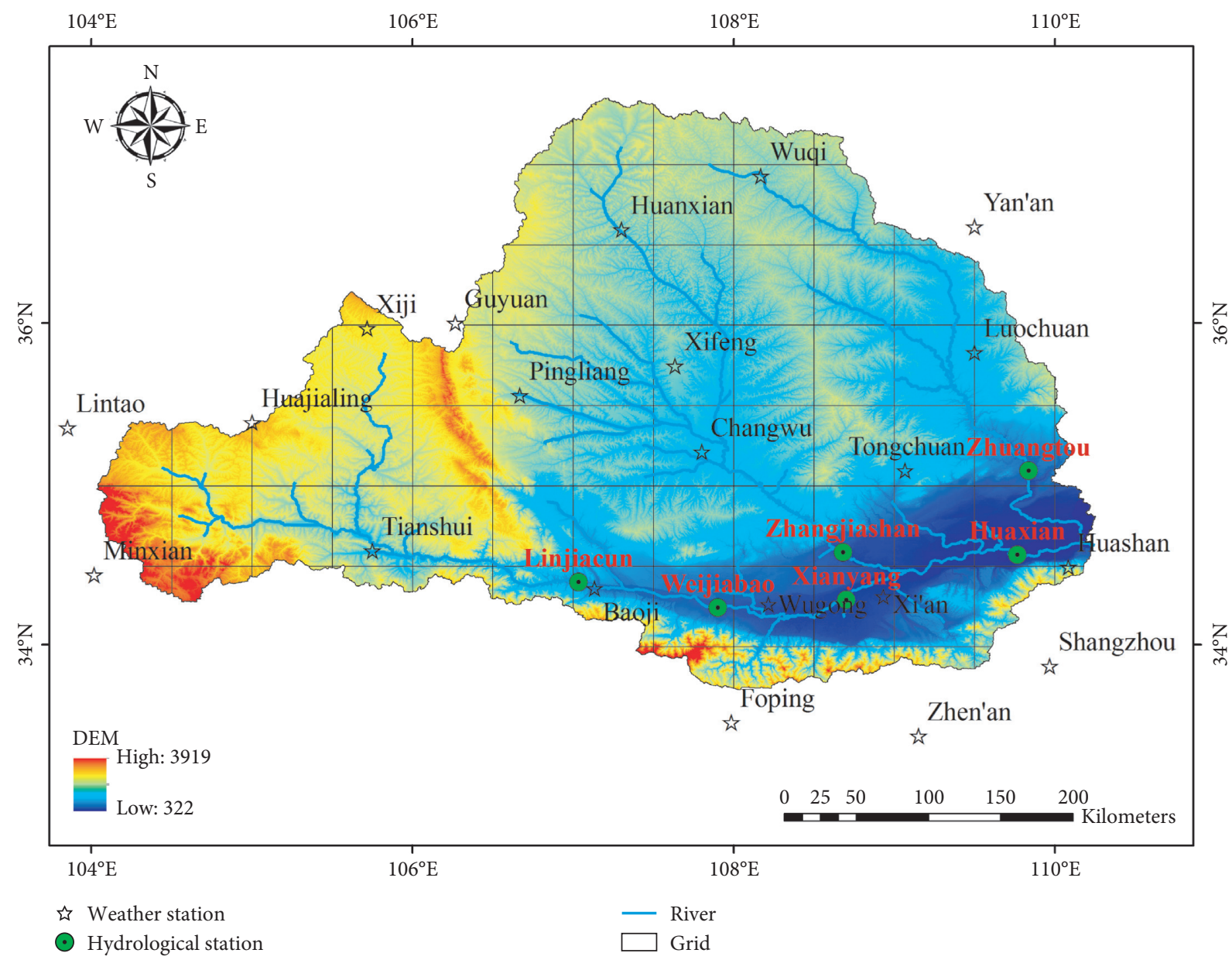

Figure 1: Mesh of the model.

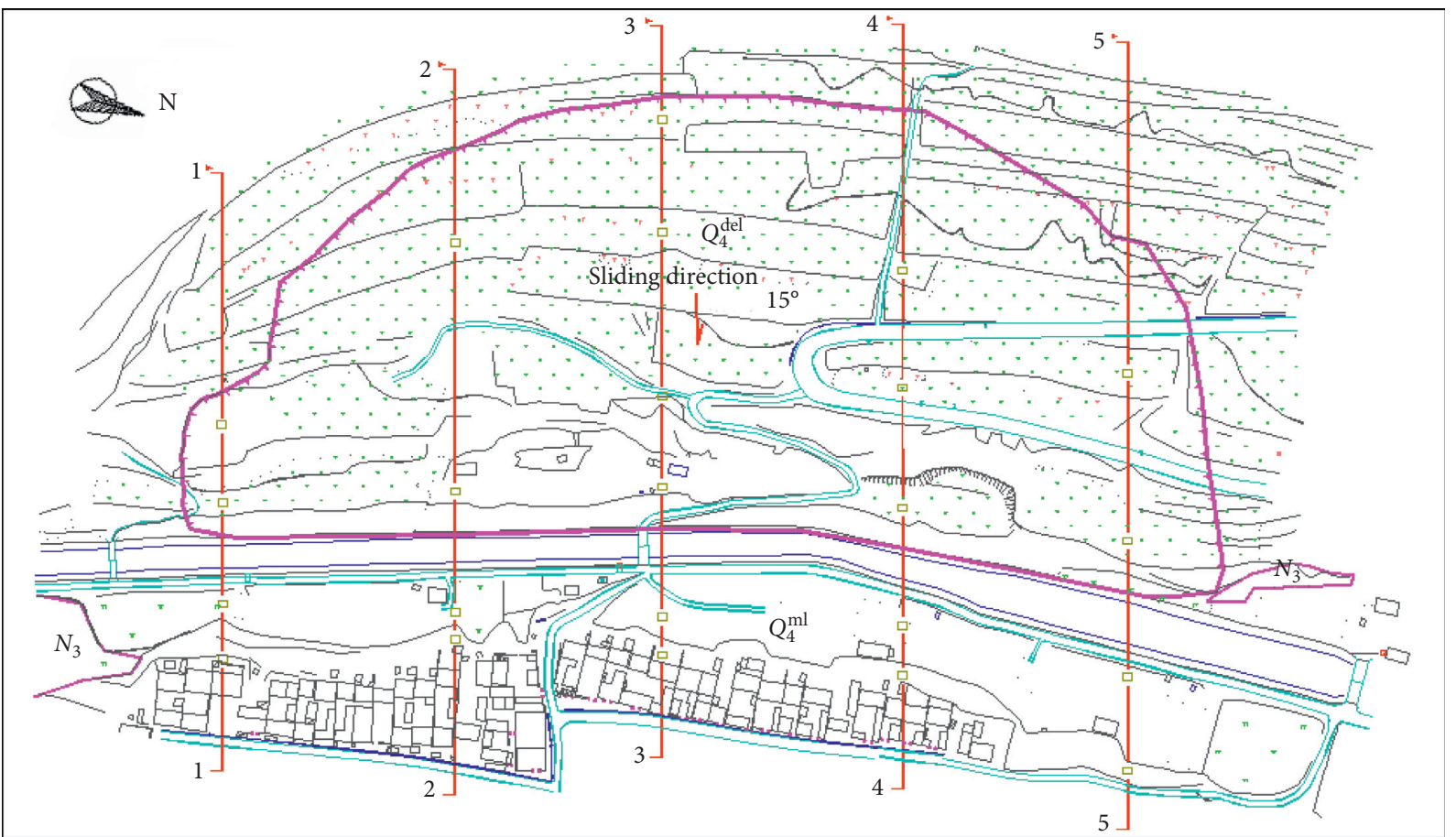

FIgure 2: The location and plan of the landslide body. 


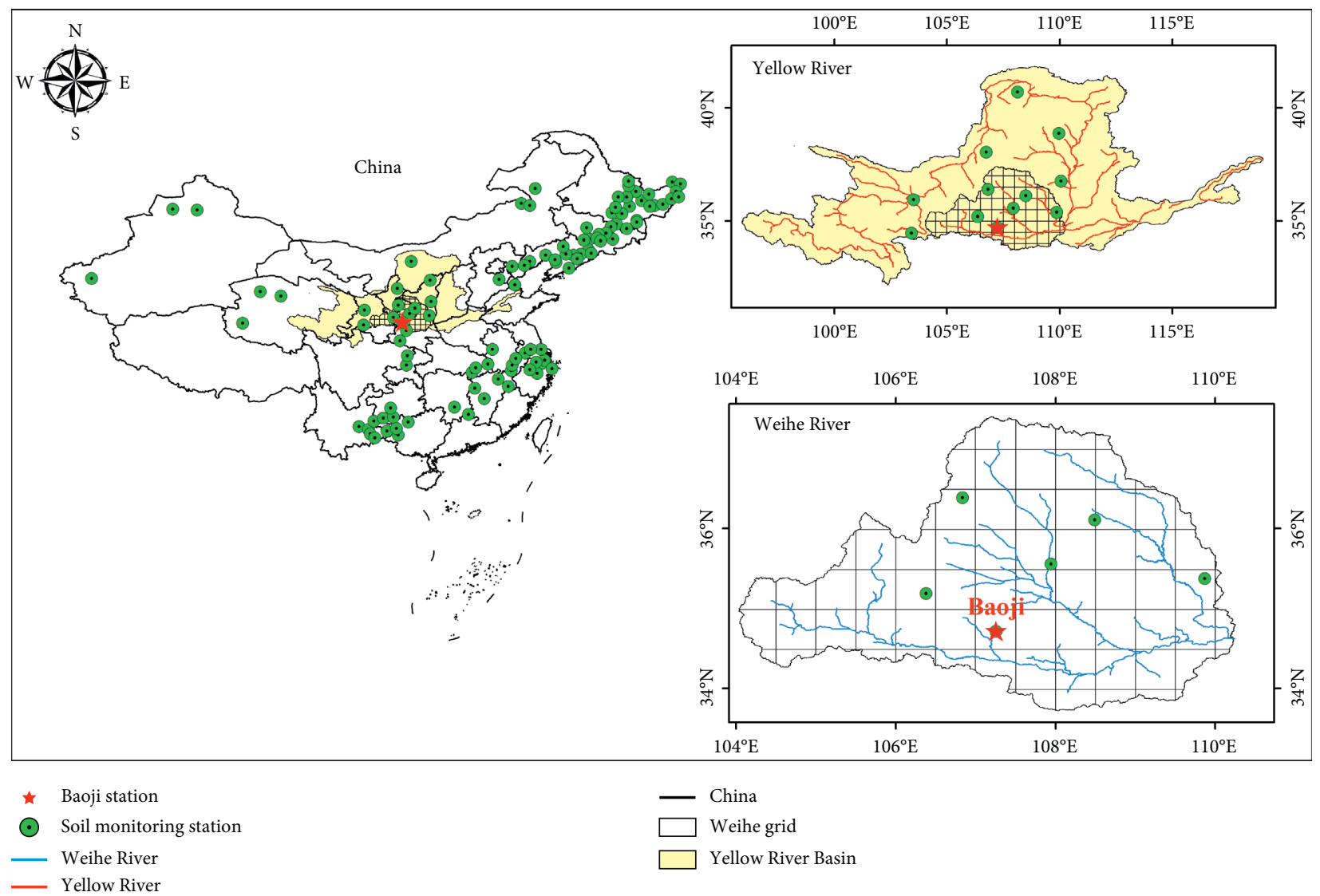

FIgURE 3: The distribution of soil monitoring stations in China and the location of the Baoji monitoring station.

interval, the relationship between moisture content and cohesion is a quadratic function, and the relationship between moisture content and the internal friction angle is a linear function; (3) in the corresponding interval, for unsaturated soil, the influence of moisture content on cohesion is greater than that on internal friction angle; and (4) when the moisture content is in the range of $5 \%$ to $20 \%$, the correlation coefficient $R$ of the above fitting formula is more than 0.90 .

3.3. M-C Inscribed Circle Criterion (DP3). In the finite element simulation, this study uses the M-C inscribed circle criterion (DP3) to judge whether the material yields. Previous studies have shown that for 3D problems, the $\mathrm{M}-\mathrm{C}$ inscribed circle criterion (DP3) is used to achieve higher accuracy and meet engineering needs [22]. This criterion was proposed by Drucker and Prager based on the Mises strength criterion in 1952, and it is expressed as follows:

$$
\alpha I_{1}+\sqrt{J_{2}}=k,
$$

where $I_{1}$ is the average stress, $J_{2}$ is the second invariant of the deviatoric stress, and $\alpha$ and $k$ are expressed as

$$
\begin{aligned}
& \alpha=\frac{\sin \varphi}{\left(\sqrt{3} \cdot \sqrt{3+\sin ^{2} \varphi}\right)}, \\
& k=\frac{3 c \cdot \cos \varphi}{\left(\sqrt{3} \cdot \sqrt{3+\sin ^{2} \varphi}\right)} .
\end{aligned}
$$

First, the cohesion $c$ and friction coefficient $\tan \varphi$ of the soil are gradually reduced, according to the traditional scheme, until the critical failure state of the slope is determined according to the criterion. Moreover, the reduction coefficient is the safety factor $k$. Second, the dynamic values of $c$ and $\varphi$ calculated according to equations (3)-(5) are substituted into the finite element model for calculation. Subsequently, the daily dynamic variation of the slope safety factor $k$, i.e., the $k$ - $t$ curve, is finally obtained, which can be used as the database to evaluate the slope safety.

3.4. $R / S$ Analysis Method. In this study, the R/S analysis method is used to analyze the consistency of the $\tau$ - $t$ and $k$ - $t$ curves. This method was first proposed by Hurst and is widely used in the analysis of time sequence [23], assuming that it can be used to determine the future development 
trend of the time sequence. The core of this method is that the time sequence must be independent of each other. For this study, both the $\tau$ - $t$ and $k$ - $t$ curves were calculated based on the daily soil moisture content generated by the VIC model. This moisture content depends on the input rainfall data. As the measured rainfall data are independent of each other, the soil moisture content generated by the VIC model is similarly independent of each other; thus, the $\tau$ - $t$ and $k-t$ curves are also independent. Therefore, it is feasible to use the RS method in evaluating the future variation trend of the slope. The principles and calculation process of the R/S analysis method can be found in references [24-26]. The classification of the variation degree is shown in Table 1 , where $C$ and $h$ are the coefficients used in determining the state of variation.

\section{Results and Discussion}

4.1. Parameter Calibration Results of VIC Model. In this study, China is divided into ten climate zones, based on China's climate zoning standard. Several study results show that the parameter range of the VIC model in China is similar to that which is shown in Table 2 [27]. The meaning of each parameter in Table 2 is as follows: $B$ pertains to the power of the variable infiltration curve, $D_{\mathrm{S}}$ refers to the proportion of the maximum value of the base flow when the base flow grows nonlinearly, $D_{\mathrm{m}}$ is the maximum base flow velocity, $W_{\mathrm{s}}$ is the moisture content ratio of the underlying soil to total soil under the condition of nonlinear base flow, and $d_{2}$ and $d_{3}$ are the thicknesses of the middle and lower layers, respectively (unit: $\mathrm{m}$ ).

The runoff from the Linjiacun, Weijiapu, Huaxian, Zhangjiashan, and Zhuangtou hydrological stations were simulated, with the calibration period covering the years from 1960 to 1969 . Due to space limitations, this paper only shows the calibration results of the Linjiacun and Weijiapu hydrometric stations of the main stream, as shown in Figure 4.

The verification period selected in this study is from 1970 to 1980 . The results of the VIC model are shown in Table 3.

For general engineering, when $E_{\mathrm{r}}<5 \%$ and $C_{\mathrm{e}}>80 \%$, it can be considered that the accuracy requirements have been met. It can be seen from Table 3 that the calculation results of each station have met the requirements, as such, it can be considered that the soil moisture output by the VIC model is consistent with that of the actual situation.

To further verify the accuracy of the VIC model results, the actual moisture content of the Baoji soil monitoring station in the grid of the landslide body shown in Figure 3 from 1981 to 1991 was compared with the simulated moisture content. The station is measured once a month (i.e., on the $\left.18^{\text {th }}\right)$, with a total of 120 water content data. The comparison results are shown in Figure 5.

The scale of the hydrological model simulation is large, whereas that of the soil moisture content coverage measured at the site is relatively smaller. The area described by the two is not in an order of magnitude. Therefore, whether the average moisture content of the grid simulated by the hydrological model is applicable to actual engineering is an
TABLE 1: Classification table of the variation degree.

\begin{tabular}{lcc}
\hline$C$ value & $h$ value & Result \\
\hline $0.8 \leq C<1.0$ & $0.924 \leq h<1.0$ & Great variation \\
$0 \leq C<0.8$ & $0.839 \leq h<0.924$ & Strong variation \\
$r_{\beta} \leq C<0.6$ & $h_{\beta} \leq h<0.839$ & Secondary variation \\
$r_{\alpha} \leq C<r_{\beta}$ & $h_{\alpha} \leq h<h_{\beta}$ & Weak variation \\
$0 \leq C<r_{\alpha}$ & $0.5 \leq h<h_{\alpha}$ & Nonvariation \\
\hline
\end{tabular}

TABle 2: Table of parameters.

\begin{tabular}{lcc}
\hline Parameter & Minimum value & Maximum value \\
\hline$B$ & 0.5 & 6 \\
$D_{\mathrm{s}}$ & 0.0325 & 0.05 \\
$D_{\mathrm{m}}$ & 2.1 & 30 \\
$W_{\mathrm{s}}$ & 0.8 & 0.85 \\
$d_{2}$ & 0.05 & 4.5 \\
$d_{3}$ & 0.4 & 1.75 \\
\hline
\end{tabular}

intensely debated issue. Dimeyer [28] believes that both can test each other. Furthermore, Wu et al. [29] believe that although the values of both are not the same, the variation trend is similar. In this study, we agree with the earlier viewpoints and hold that it is feasible to verify the variation trend of the average moisture content of the grid with the long series moisture content of the station and, thereafter, use it to represent the variation in the soil moisture content in the landslide. Figure 5 shows that the average moisture content depth of the grid is between 300 and $700 \mathrm{~mm}$ and that the measured moisture content value of the station is between 150 and $400 \mathrm{~mm}$. It can be observed that there is a large difference between the two values. The main reason for this difference is that it is limited by the site conditions and monitoring methods. The station only monitors the moisture content at the depth of 0 to $500 \mathrm{~mm}$, whereas the threelayer soil measured was $d_{1}=0.1 \mathrm{~m}, d_{2}=3.955 \mathrm{~m}$, and $d_{3}=1.0 \mathrm{~m}$, and the total thickness is $5.055 \mathrm{~m}$. Consequently, they are different in thickness and scale. Simultaneously, it can also be seen that although the values are different, the variation trends of the two are similar and that the peak valley position is relatively consistent. This conclusion is consistent with the abovementioned viewpoints of Dimeyer and $\mathrm{Wu}$, which show that the variation trend of soil moisture content simulated by the VIC model in the grid is representative and can be used in practical engineering.

\subsection{Spatial and Temporal Distribution of Soil Moisture} Content in the Study Area. The data on the precipitation series, the daily maximum and minimum temperature, and the wind speeds from 21 meteorological stations in the Weihe River Basin from 1970 to 2010 were supplied to the VIC model. Data on the daily moisture content of the grid in the study area were produced by the VIC model to simulate the dynamic change process of the soil moisture content. The soil moisture content of the VIC model is expressed as the depth of water in the soil layer (unit: $\mathrm{mm}$ ). The study period was divided into decades, i.e., 70s, 80s, 90s, and the 2000s; 


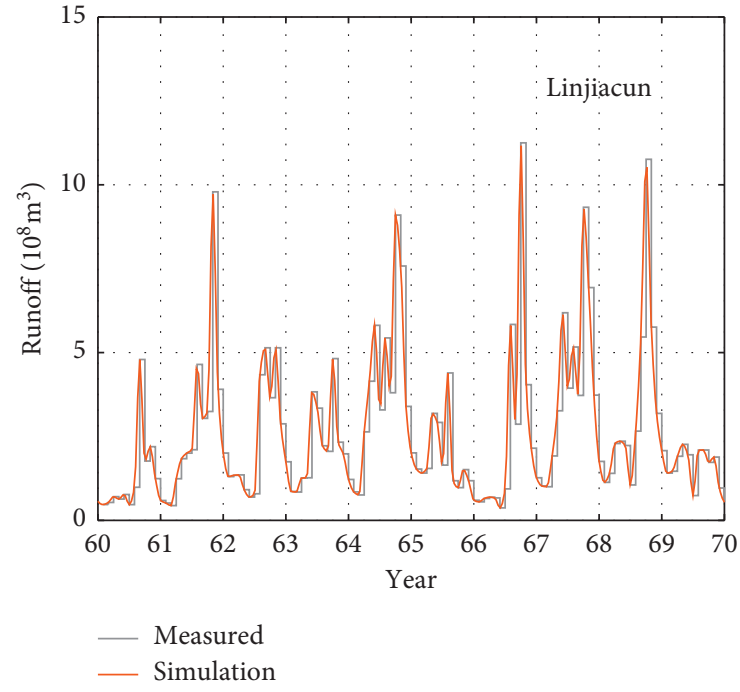

(a)

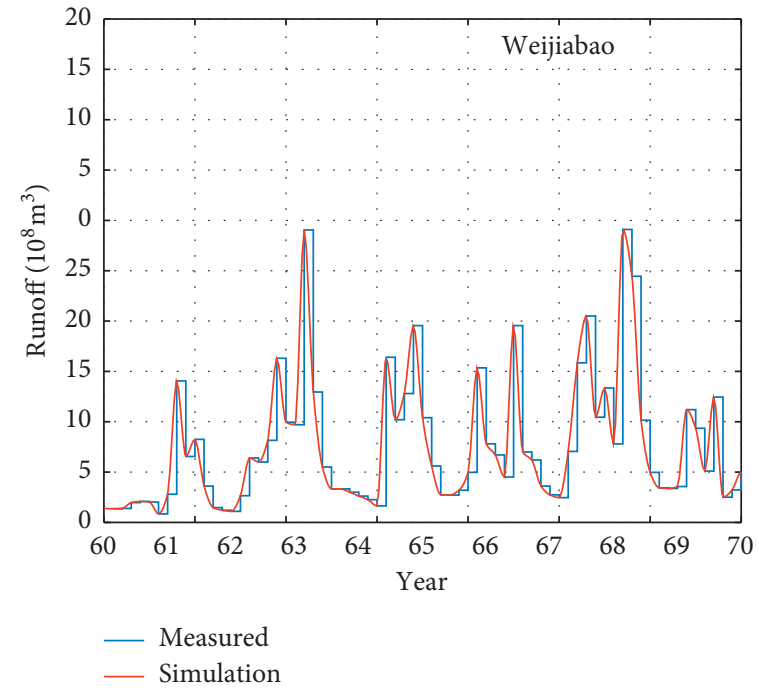

(b)

FIGURE 4: Calibration results of hydrometric stations. (a) Linjiacun station. (b) Weijiapu station.

TABLE 3: The simulation results during the validation period.

\begin{tabular}{lccc}
\hline Year & Hydrological station & $C_{\mathrm{e}}$ & \\
\hline $1970-1980$ & Linjiacun & 0.91 & 1.32 \\
$1970-1980$ & Weijiapu & 0.88 & 1.44 \\
$1970-1980$ & Zhuangtou & 0.94 & 1.18 \\
$1970-1980$ & Zhangjiashan & 0.86 & 1.52 \\
\hline
\end{tabular}

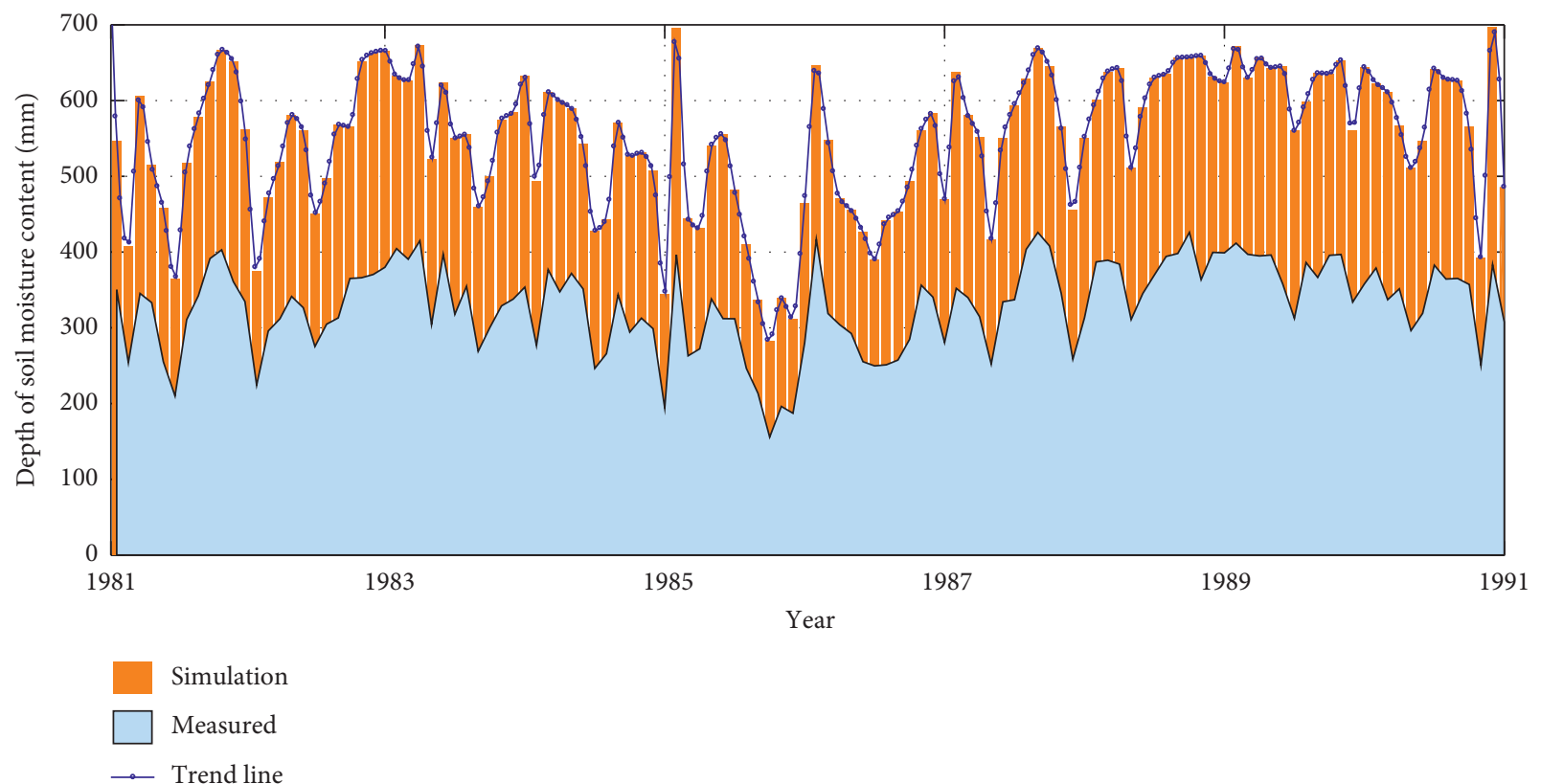

FIGURE 5: Comparison of measured and simulated soil moisture content.

and the mean value of the soil moisture in the grid of each age was calculated in days. The contour map is shown in Figure 6.

Figure 6 shows that the soil moisture content in the upper Weihe River, Jinghe River Basin, and upper Beiluo
River was generally small in the 70 s, and that the soil moisture depth in most areas is less than $300 \mathrm{~mm}$. Only in some areas of the upper Weihe River (half grid), the upper Jinghe River (one grid), the middle reaches of Beiluo River (one grid), and the lower Weihe River (seven grids) did the 


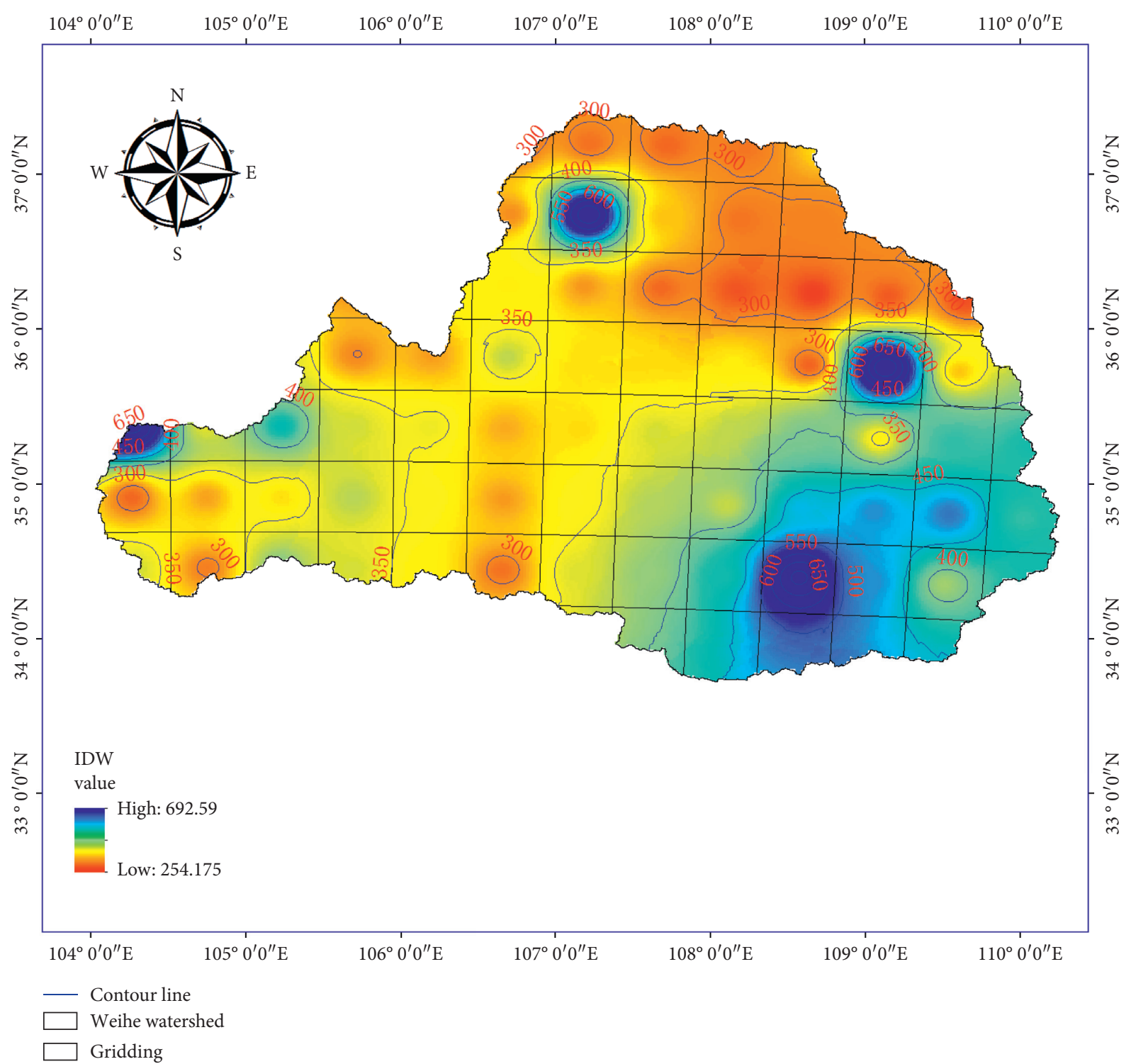

(a)

Figure 6: Continued. 


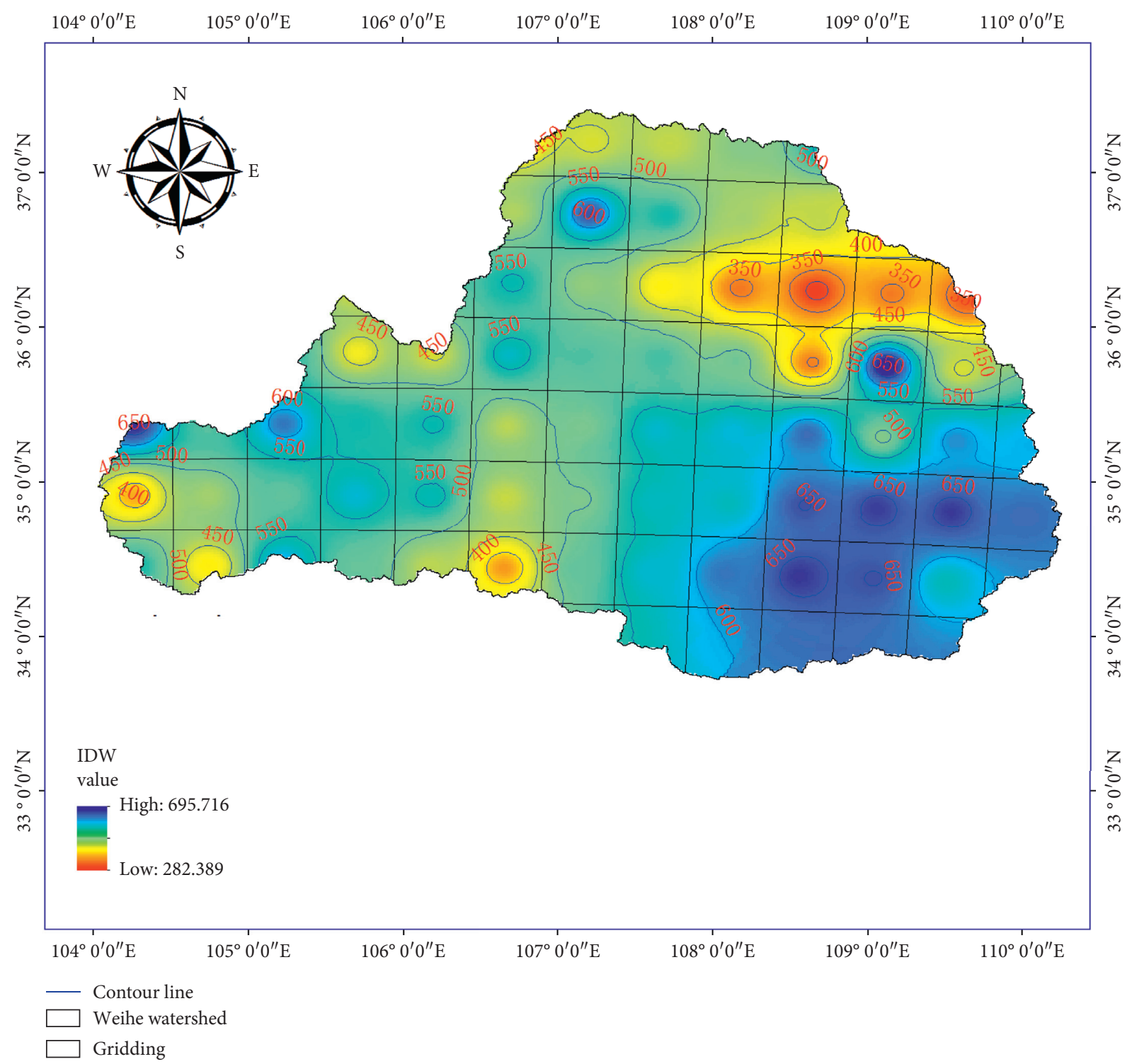

(b)

Figure 6: Continued. 


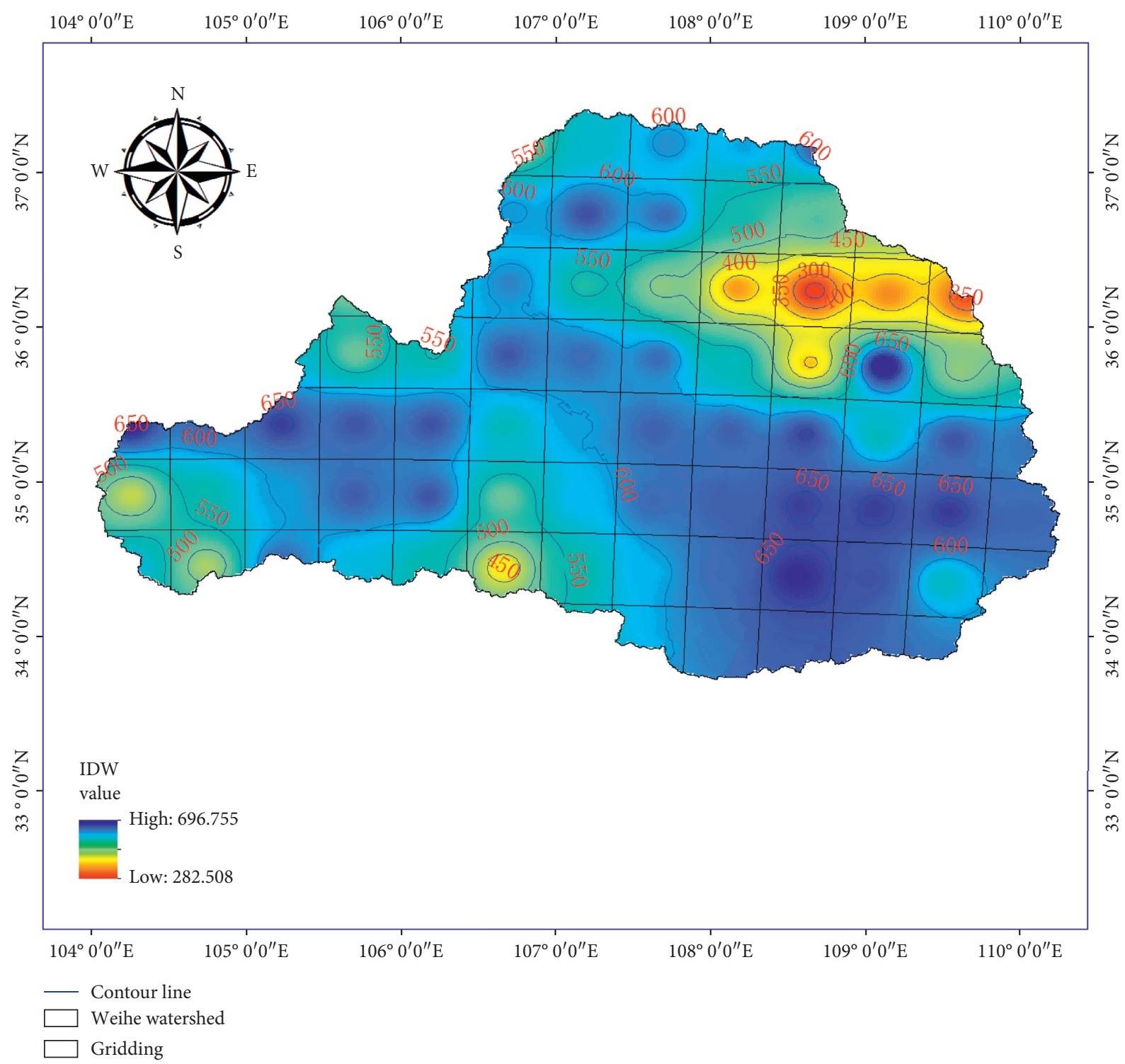

(c)

Figure 6: Continued. 


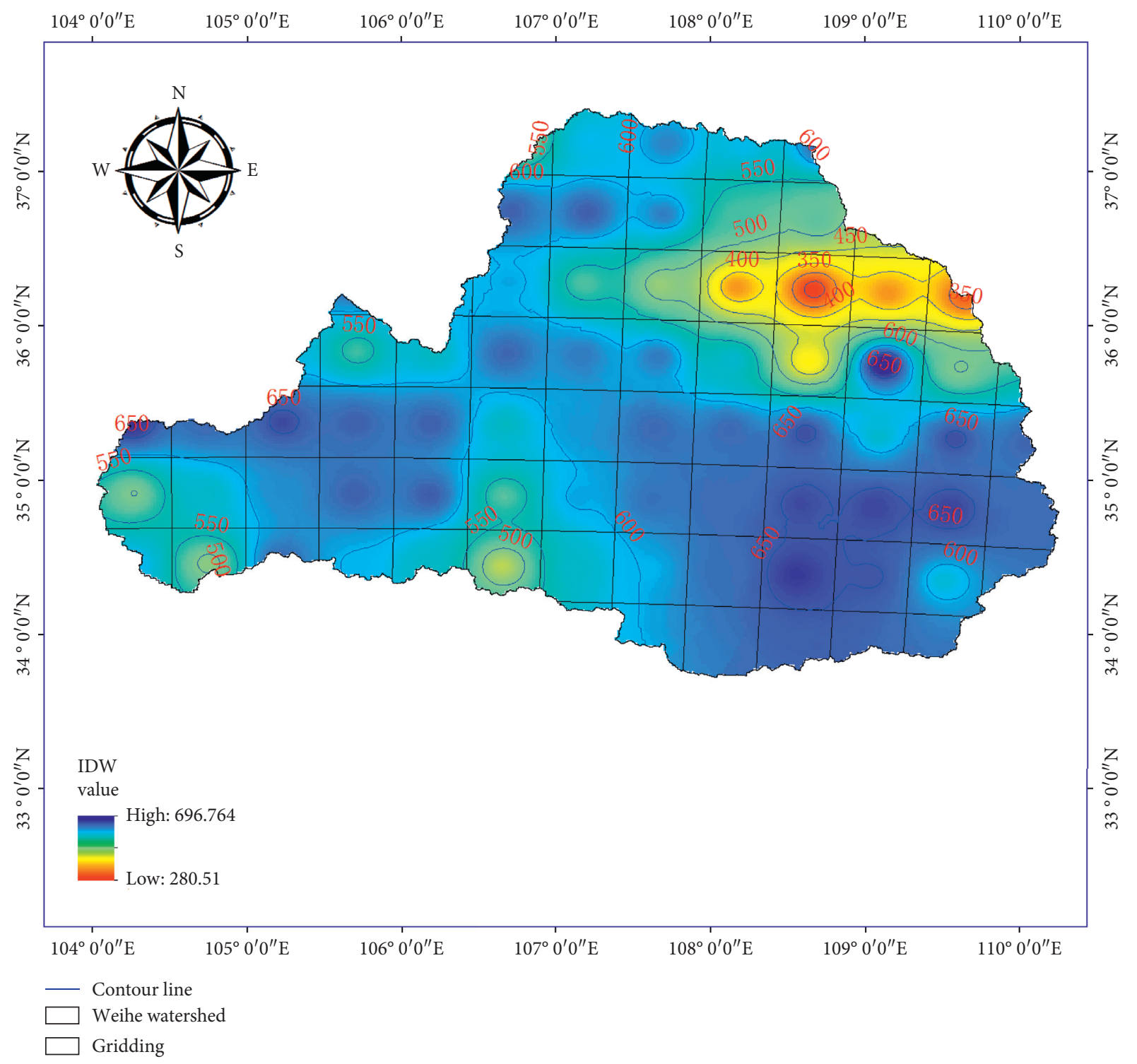

(d)

Figure 6: Soil moisture distribution in the Weihe Basin. (a) 70s, (b) 80s, (c) 90s, and (d) 2000s.

moisture content depth exceed $600 \mathrm{~mm}$. The main reason for this phenomenon is not only the local uneven rainfall, but also the type of underlying surface, vegetation coverage, and water system density in the year. The reason for the abrupt change in water content in the upper Weihe River is that part of the soil is of a grey-cinnamon kind, which has high water absorption and water retention properties. The red clay in a small part of the upper Jinghe River also has these characteristics, while the lower Weihe River and the middle reaches of the Beiluo River have viscous moist soil along with well-developed water systems and complex interlaced water networks, which are convenient for the exchange and retention of soil moisture. Since the 80 s due to the effects of climate change as well as soil and water conservation, the soil moisture depth of the grid increased gradually until the 2000s. The average moisture depth of the grid reached $650 \mathrm{~mm}$. In this study, the soil depths of the three layers were determined as $d_{1}=0.1 \mathrm{~m}, d_{2}=3.955 \mathrm{~m}$, and $d_{3}=1.0 \mathrm{~m}$; hence, the variation range of the soil moisture content in this basin is between $4 \%$ and $12 \%$, consistent with the conclusion of the existing literature [30].

The distribution of the soil moisture content in the study area exhibits a longitudinal change over time (i.e., the moisture content of the same grid is different in different years) and a transverse change along the basin (i.e., the moisture content of different grids is different at the same time). Furthermore, it is shown that the variation in the soil moisture content in the Weihe River Basin is complex. Based on the comprehensive analysis, there are two aspects of human activities and climate change: first, water and soil conservation measures, reservoir operation, river runoff diversion, riverside pumping, rainwater collection, and other human activities are the factors that affect soil moisture content change; second, changes in precipitation, 


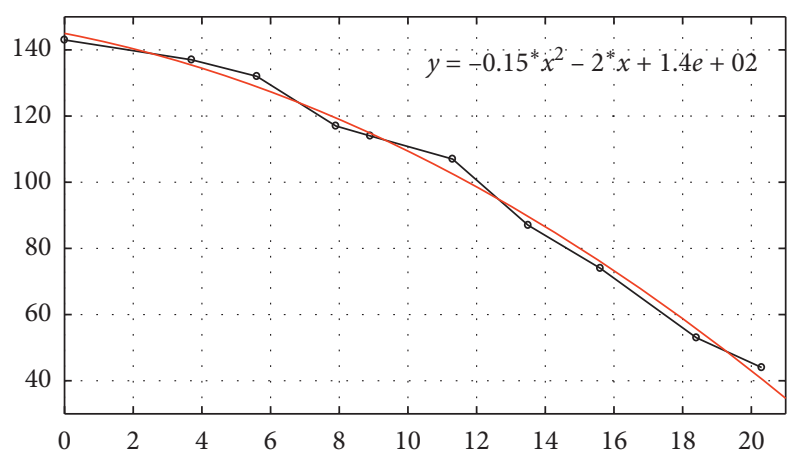

(a)

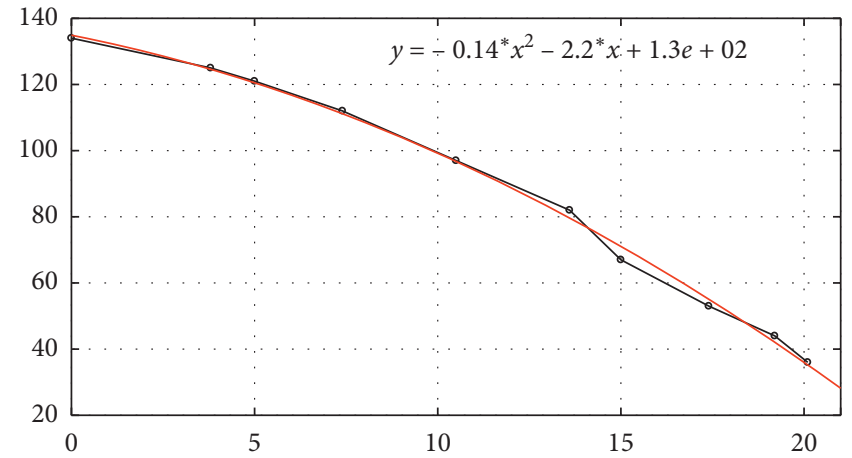

(b)

Figure 7: Moisture content-cohesion curve.

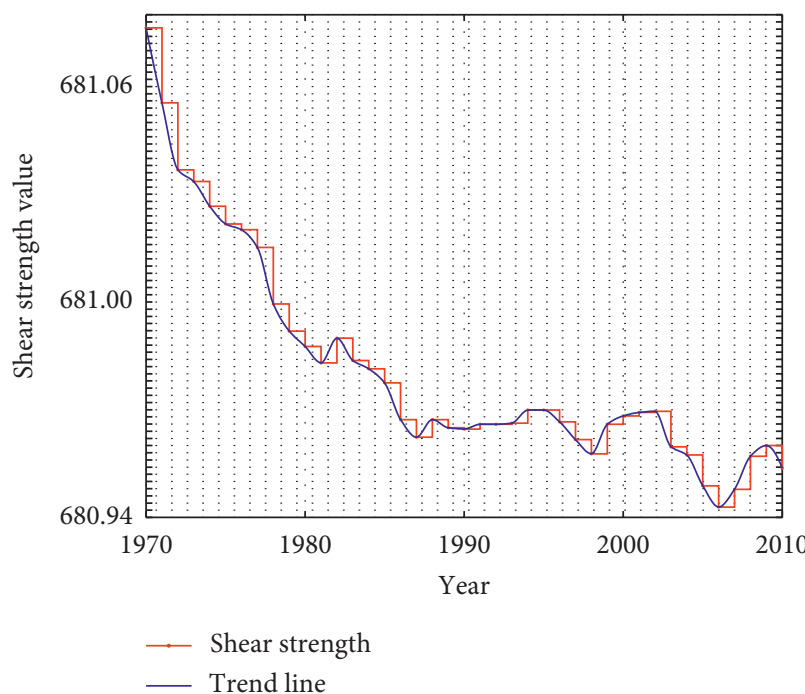

(a)

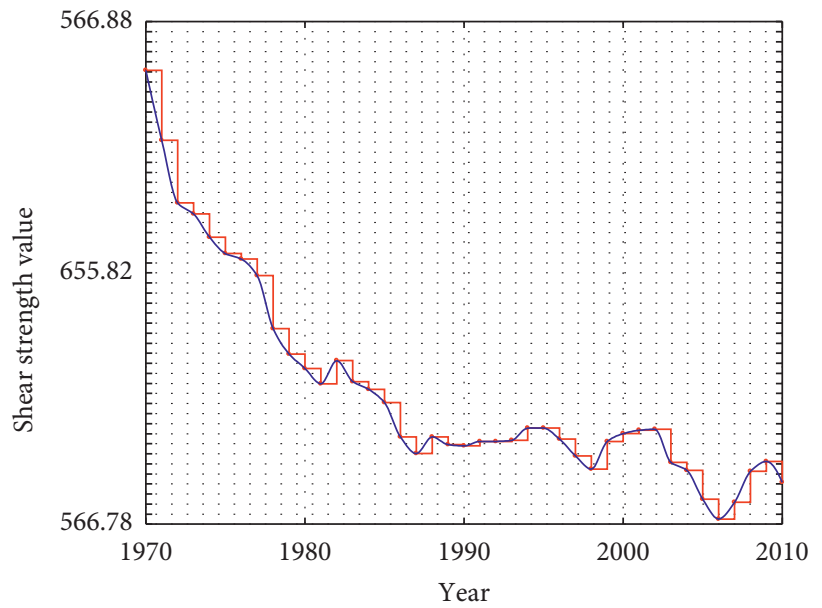

- Shear strength

_ Trend line

(c)

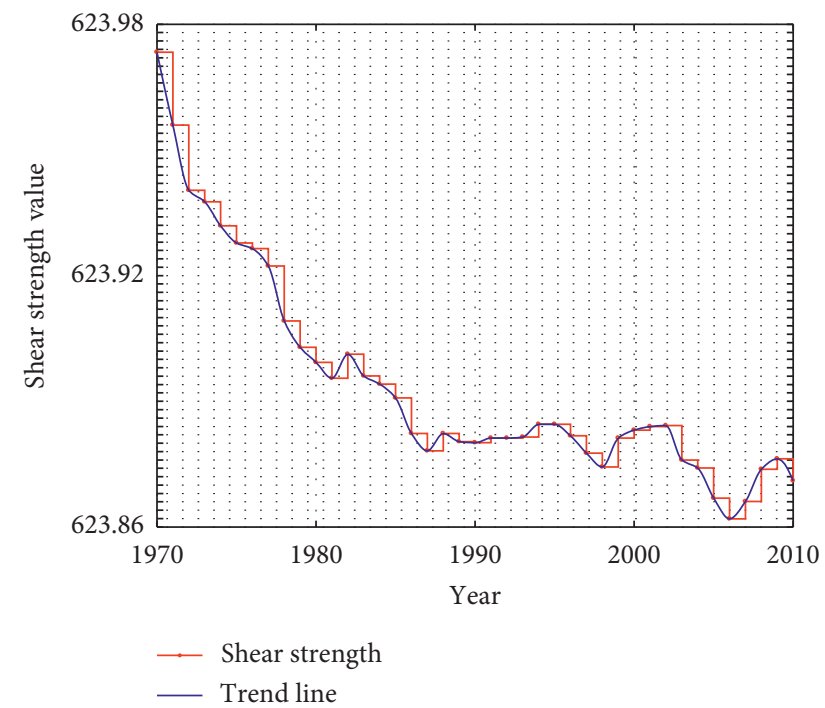

(b)

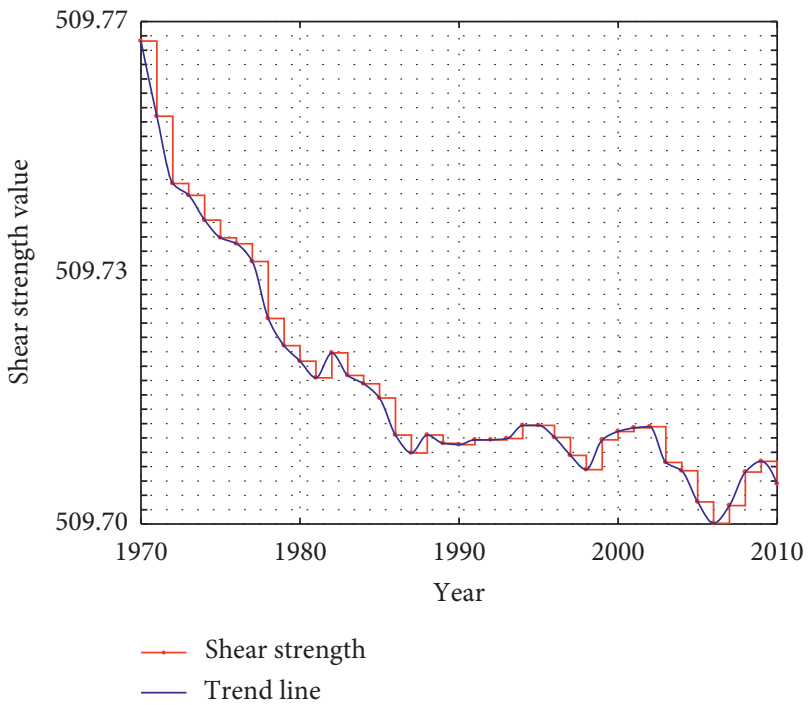

(d)

Figure 8: Shear strength-time curve. (a) $\sigma=100 \mathrm{kPa}$. (b) $\sigma=200 \mathrm{kPa}$. (c) $\sigma=300 \mathrm{kPa}$. (d) $\sigma=400 \mathrm{kPa}$. 


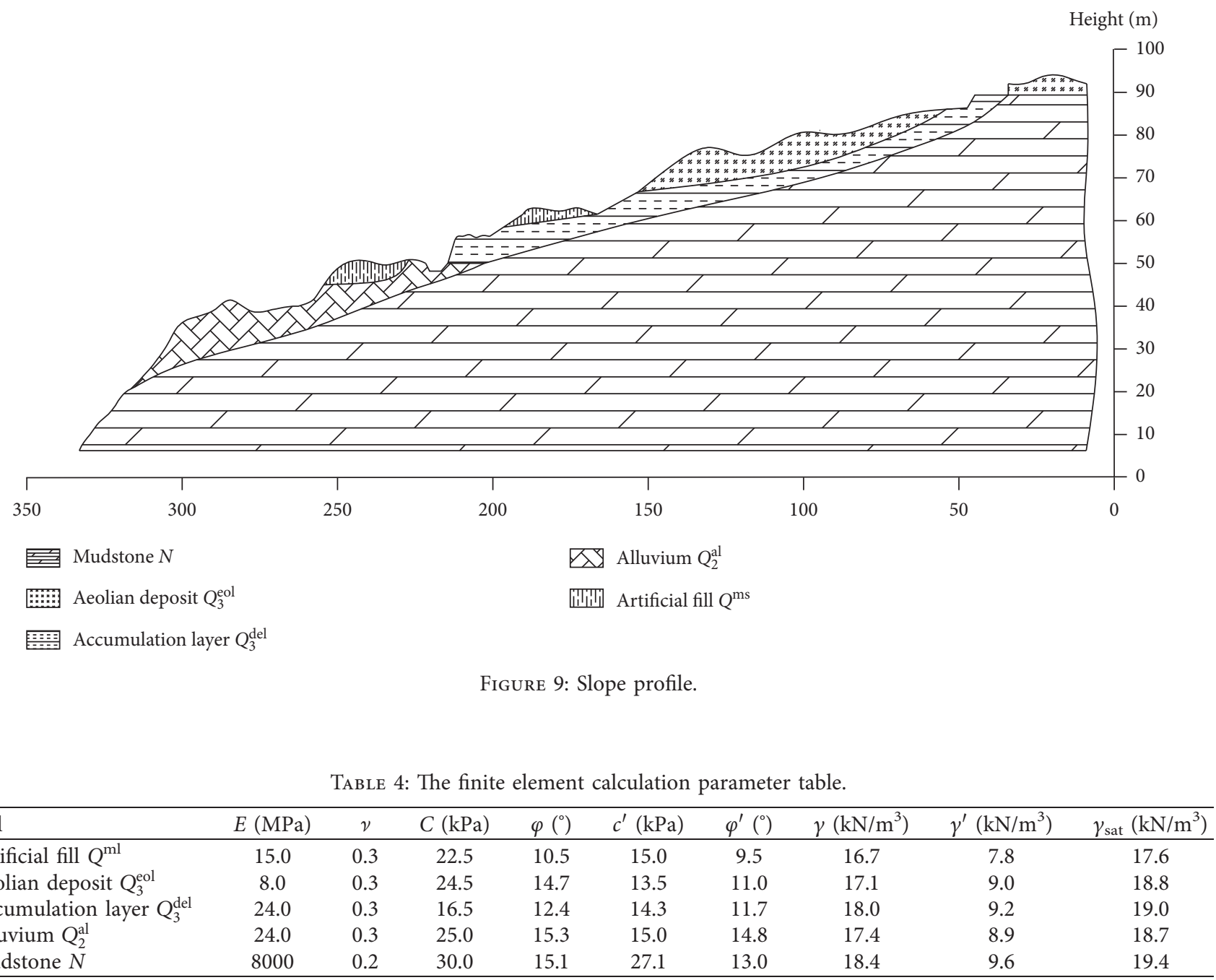

evaporation, and vegetation distribution are the other factors. Overall, most of the soil in the study area exhibited a trend of gradually increasing soil moisture for the past $40 \mathrm{y}$, thereby having a negative impact on the shear strength of soil.

4.3. Status Assessment of Slope Shear Strength. In the grid composed of $34^{\circ} \mathrm{N}-34^{\circ} 30^{\prime} \mathrm{N}$ and $107^{\circ} \mathrm{E}-107^{\circ} 30^{\prime} \mathrm{E}$ of the VIC model (the landslide body in this study is within the grid), assuming that $\sigma$ is $100 \mathrm{kPa}, 200 \mathrm{kPa}, 300 \mathrm{kPa}$, and $400 \mathrm{kPa}$, the daily moisture content from 1970 to 2010 is substituted into the fitting formula of $w-c, w-\varphi$, and $w$ - $\tau$, and the function relationship between the shear strength $\tau$ and time $t$ is calculated.

In the study area, the soil moisture content was within the range from $4 \%$ to $12 \%$. The expression of the fitting formula obtained through the experiment is $c=-0.15 \cdot w^{2}+1.31 \cdot w+110$, its correlation coefficient is $R=0.99 ; \varphi=-1.62 \cdot w+48.8$, and its correlation coefficient is $R=0.95$. Moreover, $\tau=\left(-0.15 \cdot w^{2}+1.31 \cdot w+110\right)+\sigma \tan$ $(-1.62 \cdot w+48.8)$. Considering the correlation coefficient $R$, the fitting effect of the shear strength parameter is better.
Considering the fitting diagram, taking the $w$-c curve, as shown in Figure 7, as an example, the measured scatter values are very close to the fitting result (i.e., the results of the other equations are similar). Therefore, it can be considered that the fitting equation is applicable to this project. The result of the $\tau$ - $t$ curve is shown in Figure 8 (unit: $\mathrm{kPa}$ ).

Figure 8 shows that when the normal stress $\sigma$ is constant and the shear strength of the soil in the grid is not constant but rather varies with the soil moisture content. For the grid where the landslide was located, the soil shear strength decreased from 1970 to 2005 and increased from 2005 to 2010. However, whether it goes down or up, the variation is small, i.e., approximately $2 \%$. Therefore, it can be considered that the shear strength of soil in the grid has been basically stable for the past $40 \mathrm{y}$.

4.4. Status Assessment of Slope Safety Factor. According to the engineering geological data, the slope selected in this study is a mixed slope, where the upper part is the soil layer and the lower part is the mudstone base. Thus, it is feasible to calculate and evaluate according to the plan of the soil slope. The M-C inscribed circle criterion (DP3), as shown in 

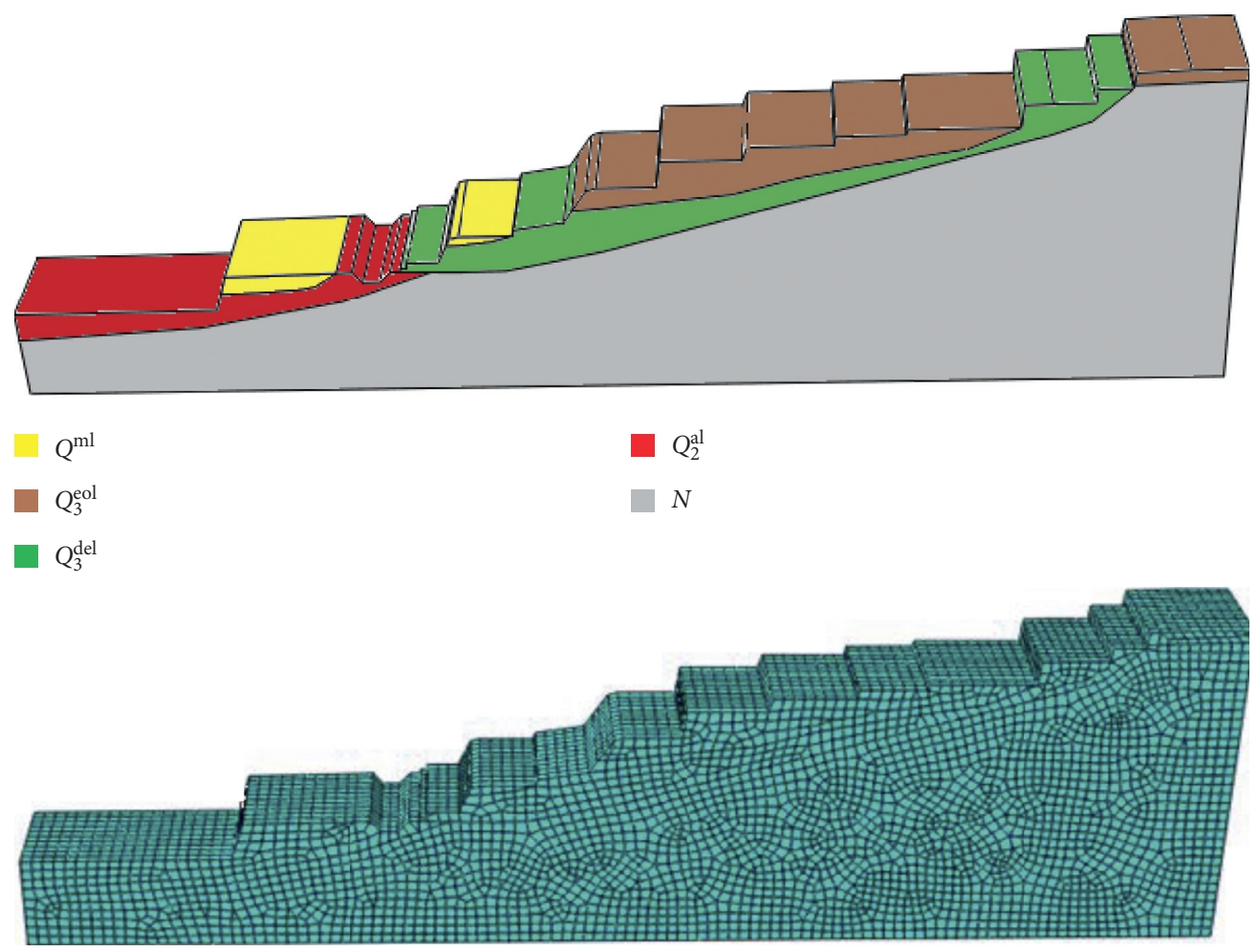

Figure 10: The finite element model and the soil material interface.

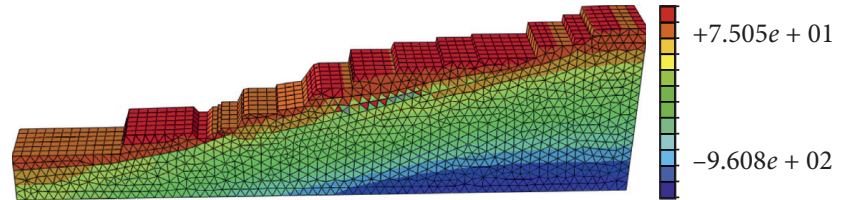

(a)

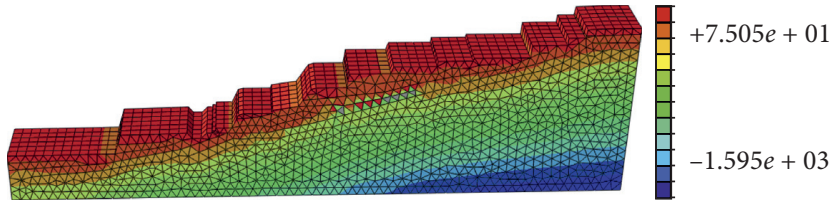

(b)

FIgURE 11: The stress contour map under critical damage condition. (a) Horizontal stress. (b) Vertical stress.

Figure 2, was selected as the finite element calculation model, which had a length of $340 \mathrm{~m}$, a height of $99.6 \mathrm{~m}$, and a width of $30 \mathrm{~m}$. The section is shown in Figure 9.

According to the drilling survey report, the section is divided into five layers from top to bottom: artificial fill $Q^{\mathrm{ml}}$, aeolian deposit $Q_{3}^{\text {eol }}$, accumulation layer $Q_{3}^{\text {del }}$, alluvium $Q_{2}^{\mathrm{al}}$, and mudstone $N$. The various soil calculation parameters are shown in Table 4.

The ABAQUS software was used to build a 3D model with 27210 cells and 31042 nodes, as shown in Figure 10.

Using the traditional calculation scheme based on the $\mathrm{M}-\mathrm{C}$ inscribed circle criterion (DP3), the horizontal stress and vertical stress in the critical failure state of the slope are shown in Figure 11. In this scheme, the initial stress field of the stratum was first calculated. When the reduction coefficient of the shear strength parameter was determined to be 1.145 , the slope accumulation layer $Q_{3}^{\text {del }}$ of the second terrace appeared as a connected plastic zone (see Figure 12). Consequently, the iterative calculation stopped, the slope was considered to be almost destroyed, and the corresponding safety factor $k$ was specified as 1.145 .
Keeping the slope model unchanged, substituting the long series data on soil moisture content into equations (4) and (5), a series of different $c$ and $\varphi$ values are obtained, while the other parameters in Table 4 remain unchanged. The parameters are processed into the finite element model for calculation, and, finally, a series of $k$ values are obtained, which are the safety factors of the slope caused by the change in moisture content from 1970 to 2010 (the $k$ value changes daily). Because of the large amount of data, in order to facilitate the analysis, this study used cubic spline interpolation to fit this series of $k$ values into a smooth curve, as shown in Figure 13, which is an important basis for the safety assessment of landslide hazards.

Figure 13 shows that the safety factor $k$ has an overall upward trend over the 40-year period. The portion of the period with a $k$ value higher than 1.2 is more than $85 \%$ of the entire period, that with a $k$ value between 1 and 1.2 is approximately $9 \%$ of the entire period, and that with a $k$ value less than 1 is approximately $5.5 \%$ of the entire period. According to the existing literature [31], when the safety factor $k$ of the slope is greater than 1.15 , the slope is in a safe 


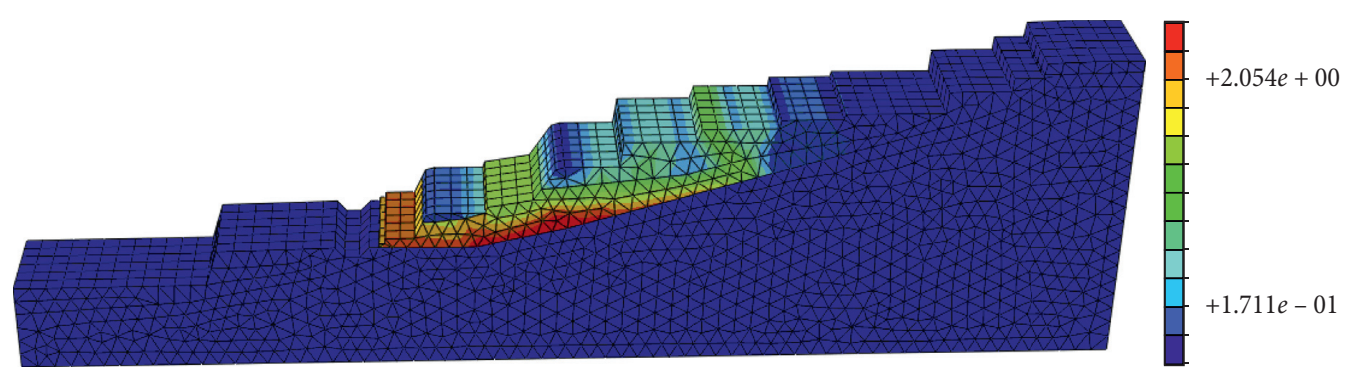

Figure 12: The total equivalent plastic strain contours under critical damage condition.

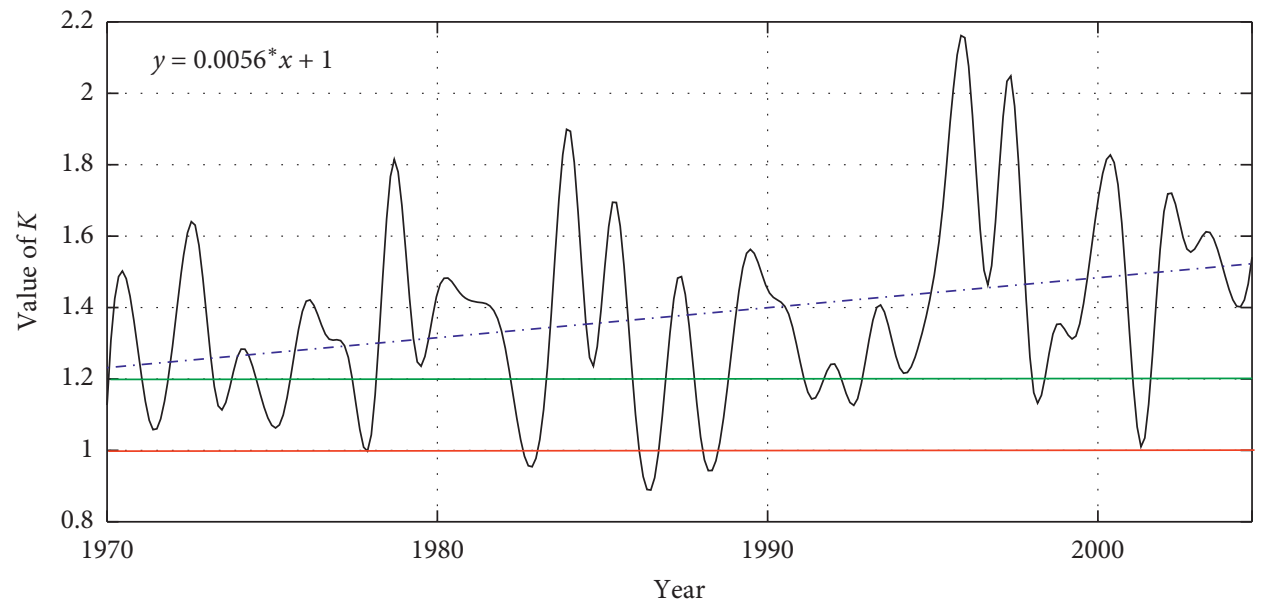

FIgURE 13: Long series $k$ - $t$ fitting curve.

state; when it is between 1 and 1.15 , the slope is in an unstable state; and when it is less than 1, the slope is in a dangerous state. Therefore, from the macrostate of 40 years, the slope is shown to have been safe for most of the time covered therein, i.e., it was only in the 80 s where a possible dangerous state existed, but a landslide did not happen during that period. Historical investigation data records show that there was deformation adjustment along the boundary of the landslide body induced by continuous rainfall around 1983, which is consistent with the results of this study.

4.5. Future Stability Assessment of the Slope. Taking the significance level $\alpha=0.05$ and $\beta=0.01$, the R/S analysis results of the $\tau$ - $t$ sequence are $h=0.5568$ and $h_{\alpha}=0.6033$ and the analysis results of the $k$ - $t$ sequence are $h=0.5888$ and $h_{\alpha}=0.6310$. According to the classification in Table 1, from the perspective of shear strength or that of safety factor, in the future, the slope belongs to the nonvariable state; i.e., the slope will still be in a stable state.

\section{Conclusions}

In this study, the extensively distributed hydrological model VIC was used to study the temporal and spatial variation law of soil shear strength and slope safety factor. First, the hydrological model was applied on a macroscale, taking the precipitation, temperature, soil type, and vegetation cover as the input data and the daily moisture content of the grid as the output data. Moreover, the relationship between moisture content, shear strength, and slope safety factor was discussed, and the change in slope stability was evaluated on an interannual scale. Furthermore, we proposed a new method for evaluating the stability of slopes from the hydrological perspective. The conclusions of this study are as follows:

(1) From 1970 to 2010, the average range of variation of the daily soil moisture content output using the VIC model in the Weihe River Basin was from $4 \%$ to $12 \%$. The monitoring results of the moisture content monitoring station showed that the soil moisture content generated by the model had similar variation trend as the measured value. Consequently, it was considered that the method of estimating the soil moisture content by the hydrological model was feasible in this basin.

(2) The shear strength of soil is related to the variation in the moisture content. Under the four normal stress conditions assumed in the present study, the shear strength of the slope exhibited a downward trend from 1970 to 2005 and a rebound trend from 2005 to 2010 , but the overall variation range did not exceed $2 \%$. Considering the shear strength of the soil, the slope was basically stable for the past $40 \mathrm{y}$.

(3) The finite element calculation results show that from 1970 to 2010, the period with $k$ values higher than 1.2 
comprised more than $85 \%$ of the entire period, that with $k$ values between 1 and 1.2 comprised approximately $9 \%$ of the entire period, and that with $k$ values less than 1 comprised approximately $5.5 \%$ of the entire period. Therefore, considering the safety factor, it was shown that the slopes were stable for the past $40 \mathrm{y}$.

(4) The results of the R/S analysis show that the Hurst coefficient of the shear strength-time sequence is 0.5568, the Hurst coefficient of the safety factor time sequence is 0.5888 , and the slope is in the state of no variation; hence, the slope will remain stable in the future.

\section{Data Availability}

The data used to support the findings of this study are available from the corresponding author upon request.

\section{Conflicts of Interest}

The authors declare that they have no conflicts of interest.

\section{Acknowledgments}

The financial support was provided by the Natural Science Foundation of Jiangxi Provincial Department of Education (GJJ180954) and the project of Hubei University of Arts and Science (2020kypyfy035).

\section{References}

[1] Y. L. Zhu and G. P. Qi, "Linkages between precipitation cycle and slope stability: a case study in the Caijiapo land slide among Weihe River Basin," Conference Series: Earth \& Environmental Science, vol. 82, no. 1, Article ID 012092, 2017.

[2] D. G. Fredlund and H. Rahardjo, Unsaturated Soil Mechanics, China Architecture \& Building Press, Beijing, China, 1997.

[3] Z. J. Shen, "The problems in the present studies on mechanics for unsaturated soil," in Proceedings of the Symposium on Geotechnical Aspects of Regional Soils, Atomic Energy Press, Nanjing, China, 1996.

[4] N. Khalili and M. H. Khabbaz, "A unique relationship for $\chi$ for the determination of the shear strength of unsaturated soils," Géotechnique, vol. 48, no. 5, pp. 681-687, 1998.

[5] A. Ali, J. Huang, A. V. Lyamin, S. W. Sloan, and M. J. Cassidy, "Boundary effects of rainfall-induced landslides," Computers and Geotechnics, vol. 61, no. 4, pp. 341-354, 2014.

[6] W. Zhu, N. J. Cheng, X. J. Chen, and Z. H. Zhao, "Some fundamental problems of unsaturated seepage," Chinese Journal of Geotechnical Engineering, vol. 28, no. 2, pp. 235240, 2006.

[7] H. J. Liao, Q. Sheng, S. H. Gao, and Z. P. Xu, "Influence of draw down of reservoir water level on landslide stability," Chinese Journal of Rock Mechanics and Engineering, vol. 24, no. 19, pp. 3454-3458, 2005.

[8] M. Rahimi and M. Faza, "Characterization of shallow landslide through rainfall model," Tissue Antigens, vol. 57, no. 1, pp. 80-92, 2013.

[9] S. Segoni, L. Leoni, A. I. Benedetti et al., "Towards a definition of a real-time forecasting network for rainfall induced shallow landslides," Natural Hazards and Earth System Science, vol. 9, no. 6, pp. 2119-2133, 2009.

[10] D. Xian and Z. K. Yang, "Stability of unsaturated slop under different initial water contents," Bulletin of Soil and Water Conservation, vol. 38, no. 3, pp. 123-129, 2018.

[11] D. Tang, Characteristic of unsaturated soil and slope stability analysis considering antecedent rainfall, Ph.D. thesis, Wuhan University, Wuhan, China, 2016.

[12] Y. Y. Zhang, Study on rainfall-induced landslide stability under runoff-infiltration coupled effect, Ph.D. thesis, Chongqing University, Chongqing, China, 2018.

[13] D. L. Sun, Mapping landslide susceptibility based on machine learning and forecast warning of landslide induced by rainfall, Ph.D. thesis, East China Normal University, Shanghai, China, 2019.

[14] X. Liang, D. P. Lettenmaier, E. F. Wood, and S. J. Burges, “A simple hydrologically based model of land surface water and energy fluxes for general circulation models," Journal of Geophysical Research, vol. 99, no. D7, pp. 14415-14428, 1994.

[15] X. Liang and Z. Xie, "A new surface runoff parameterization with subgrid-scale soil heterogeneity for land surface models," Advances in Water Resources, vol. 24, no. 9-10, pp. 1173-1193, 2001.

[16] Z. H. Xie, F. G. Su, X. Liang, Q. C. Zeng, Z. C. Hao, and Y. F. Guo, "Applications of a surface runoff model with Horton and Dunne runoff for VIC," Advances in Atmospheric Sciences, vol. 20, no. 2, pp. 165-172, 2003.

[17] A. Robock, K. Y. Vinnikov, G. Srinivasan et al., "The global soil moisture data bank," Bulletin of the American Meteorological Society, vol. 81, no. 6, pp. 1281-1299, 2000.

[18] Y. L. Zhu and J. X. Chang, "Calibration of parameters for VIC model based on uniform design method," Journal of Northwest A \& F University (Natural Science Edition), vol. 43, no. 12, pp. 217-224, 2015.

[19] K. T. Fang, Uniform Design and Uniform Design Table, Science Press, Beijing, China, 1994.

[20] K. T. Fang, "Theory, method and application of uniform experimental design: a historical review," Journal of Applied Statistics and Management, vol. 23, no. 3, pp. 69-80, 2004.

[21] J. M. Bian and B. T. Wang, "Research on influence of water contents on the shear strength behavior of unsaturated soils," Chinese Journal of Underground Space and Engineering, vol. 7, no. 1, pp. 17-21, 2011.

[22] D. Y. Xie, Y. P. Yao, and F. N. Dang, Advanced Soil Mechanics, Higher Education Press, Beijing, China, 2008.

[23] B. B. Mandelbrot and J. R. Wallis, "Computer experiments with fractional Gaussian noises: part 1, averages and variances," Water Resources Research, vol. 5, no. 1, pp. 228-241, 1969.

[24] J. Zhao and X. H. Dang, “An optimal spatial structure model of urban agglomeration and its application based on fractal theory," Journal of Xi'an University of Technology, vol. 28, no. 2, pp. 240-246, 2012.

[25] X. S. Xu, L. L. Ma, and Y. B. Chen, "Theoretical basis of R/S analysis: fractional Brownian motion," Journal of Wuhan University (Natural Science Edition), vol. 50, no. 5, pp. 547550, 2004.

[26] Y. L. Zhu, J. X. Chang, and C. Y. Liu, "The research on the hydrological variation diagnosis of the Weihe River Basin," Journal of Xi'an University of Technology, vol. 30, no. 2, pp. 170-174, 2014.

[27] Z. X. Xu, Hydrological Model, Science Press, Beijing, China, 2009. 
[28] P. A. Dimeyer, "Problems in initializing soil wetness," Bulletin of the American Meteorological Society, vol. 76, pp. 2234-2240, 1995.

[29] Z. Y. Wu, G. H. Lu, J. Y. Zhang, and Y. Yang, "Simulation of daily soil moisture using VIC Mode," Scientia Geographica Sinica, vol. 27, no. 3, pp. 359-364, 2007.

[30] Q. Xue, Y. M. Tang, P. P. Sun, and J. B. Bi, “Temporal-spatial distribution of soil water content in loess slope subjected to rainfall infiltration," Bulletin of Soil and Water Conservation, vol. 34, no. 2, pp. 53-56, 2014.

[31] D. Y. Xie, B. H. Li, and S. J. Shao, Geotechnical Engineering, Higher Education Press, Beijing, China, 2008. 